\title{
A preliminary investigation on the effects of polpala (Aerva lanata) on the structure and function of urinary tract of rats
}

\author{
H. M. D. R. Herath', *M. Gunatilake², D. Lokuhetty ${ }^{3}$, J. Wijayabandara ${ }^{4}$
}

The Ceylon Journal of Medical Science 2005; 48: 33-41

\begin{abstract}
Polpala (Aerva lanata) is a medicinal plant that is extensively used for the treatment of renal disease in Ayurvedic medicine. This preliminary investigation was carried out to evaluate the diuretic effect of the crude aqueous plant extract and high and low molecular mass fractions of this herb, using the hydrated rat assay technique. Possible toxicological effects on renal structure and function, mediated by long term administration of aqueous plant extract was also studied using two concentrations of both fresh and dried plant material, made according to Ayurvedic system of medicine in Sri Lanka. Urine output, osmolality and electrolyte excretion were measured to evaluate diuretic activity. Creatinine clearance and histopathological studies were done to evaluate toxicological effects on renal structure and function.
\end{abstract}

Crude aqueous plant extract showed a diuretic activity with marked increase in urine output, urine osmolality and urinary potassium excretion. Low molecular mass fraction of dried plant material showed a significant diuretic effect while the high molecular fraction did not have the same effect. Investigations also showed that long term administration of the aqueous extract of this plant had no toxicological effects on renal structure and function of rats.
Key words: polpala, Aerva lanata, diuretic activity, toxicological effects.

\section{Introduction}

Aerva lanata Linn. (Sinhala: polpala, polkudupala, pahanabaya, puswenna. Tamil: sirupulai, thengapookeerai) which belongs to the family Amaranthaceae is a medicinal plant which is used by Ayurvedic practitioners in Sri Lanka to treat various conditions such as lithiasis, headache and renal disease (1). This plant is used in other countries too as a diuretic and anthelmintic. It is also used in malarial fever, diabetes and gonorrhea $(2,3,4,5)$. The whole plant or parts of it is used as a diuretic, herbal drink, tea, porridge, extract or as a decoction with other herbs (5).

Diuretic activity of this herb had been subjected to research by several research groups in the recent past. Two had been carried on humans and one on rats $(6,7,8)$. Experiments carried out by two research groups showed the diuretic effect of $A$. lanata when given to humans and rats. Also A. lanata is not prescribed by Ayurvedic physicians as a decoction or as a herbal drink for more than 7 days as there is a general belief that it can damage the renal structure. However, this is not scientifically proved

1. Formerly of the Department of Chemistry, Faculty of Science, University of Colombo, Sri Lanka.

2, 3 \& 4. Departments of Physiology, Pathology \& Pharmacology, Faculty of Medicine, University of Colombo, Kynsey Road, Colombo 8, Sri Lanka.

* Author for correspondence 
and people use $A$. lanata as a herbal drink or porridge according to their own interest.

This preliminary investigation was therefore conducted to evaluate the diuretic activity of crude aqueous extracts of dried and fresh plants and high and low molecular mass fractions of the dried plant using the hydrated rat assay technique (9). Also investigations were conducted to study any possible toxicological effects on renal structure and function mediated by the long term administration of aqueous extract of A. lanata.

\section{Material and Methods}

\section{Animals}

Rats for the experiments were obtained from an inbred colony maintained at the animal house of the Faculty of Medicine, Colombo. They were Sprague-Dawley male rats, in the age of 3-4 months, weighing $200 \pm 15 \mathrm{~g}$. The animals were housed in cages under tropical laboratory conditions (room temperature $28 \pm 3^{\circ} \mathrm{C}$ ) and provided a standard laboratory diet and water. Ethical review for the experiments was obtained from the Ethical Review Committee of the Faculty of Medicine, Colombo.

\section{Plant material and sample preparation}

Whole plants of $A$. lanata were collected from waste and cultivated grounds in the Gampaha District, Western Province, Sri Lanka. Botanical identity of the plant was determined using herbarium specimens available at the Department of Botany, University of Colombo, Sri Lanka.

In this investigation, $A$. lanata was used in the form of fresh plant as well as in the dried form. Dried form was prepared by keeping fresh plant (washed and cut) in an oven at $60^{\circ} \mathrm{C}$ until a constant weight was obtained. The plant extract was prepared according to the method used by ayurvedic practitioners by boiling the samples with water until the volume is reduced to half. Amounts of $50 \mathrm{~g}$ and $100 \mathrm{~g}$ of $A$. lanata used in the present study were based on amounts used in previous investigations by Udupihille and Jiffery (6). The extracts were therefore prepared by boiling either $50 \mathrm{~g}$ or $100 \mathrm{~g}$ of the plant in $400 \mathrm{ml}$ of water until the volume was halved. Then the extracts were cooled and filtered through Whatmart filter paper No. 1. Four solutions were prepared according to the above procedure. They were

Solution 1 - Extract of $A$. lanata using $50 \mathrm{~g}$ of fresh plant in $200 \mathrm{ml}$ (AL50FR)

Solution 2 - Extract of $A$. lanata using $100 \mathrm{~g}$ of fresh plant in $200 \mathrm{ml}$ (AL100FR)

Solution 3 - Extract of A. lanata using $50 \mathrm{~g}$ of dried plant in $200 \mathrm{ml}$ (AL50DR)

Solution 4 - Extract of $A$. lanata using $100 \mathrm{~g}$ of dried plant in $200 \mathrm{ml}$ (AL100DR)

Findings of the experiments with rats treated with $A$. lanata were compared with those from animals administered water, (negative control) and frusemide (used as a reference diuretic drug, positive control).

\section{Separation of high and low molecular mass fractions}

One liter of $100 \mathrm{~g} / 200 \mathrm{ml}$ dried plant extract was prepared according to the method mentioned above. Freeze-dried product of this extract was obtained by means of a freeze-dryer and yielded $30 \mathrm{~g}$. Ten grams of the freeze-dried powder was reconstituted in $250 \mathrm{ml}$ of distilled water and transferred into a previously prepared dialysis tube in $50 \mathrm{ml}$ portions and dialysed against distilled 
water (dialysis medium) contained in a flask, and continuously stirred using a magnetic stirrer. The dialysis medium was replaced several times with distilled water until it remained colorless. Pooled samples of the dialysis medium collected during the dialysis period were freeze-dried to obtain the low molecular dry powder $(6.28 \mathrm{~g})$. The high molecular mass fraction, which remained inside the tube, was also freezedried to obtain a dry powder of high molecular mass compounds $(2.94 \mathrm{~g})$. Two solutions were prepared after reconstituting high and low molecular dry powder fractions in water. These solutions contained dry powder equal to $100 \mathrm{~g} / 200 \mathrm{ml}$ extract.

\section{Experiment 1 - Screening for diuretic activity of crude aqueous plant extract}

The method used to study the diuretic activity of the extract was similar to the method used by Sripanidkuichi et al (10). Rats were fasted overnight with free access to drinking water. They were given $18 \mathrm{ml} / \mathrm{kg}$ body weight of water one hour prior to the following experiment. This dose was calculated on the basis of weight ratio between human and rats (11). Water or food was not allowed during the experimental period $(8,9)$.

Thirty six rats were randomly divided into six groups ( $n=6$ for each group) and rats in the different groups were treated as follows:

Group 1-Distilled water (control)

Group 2 - AL 50 FR

Group 3 - AL 100 FR

Group 4 - AL 50 DR

Group 5 - AL 100 DR

Group 6 - Frusemide $(20 \mathrm{mg} / \mathrm{kg}$ body weight of rat)
All solutions were administered orally via a metal oro-gastric tube. All were administered doses of $18 \mathrm{ml} / \mathrm{kg}$ body weight of rat (11). Each animal was then placed in separate metabolic cages and urine was collected into tubes fitted to the funnel at the bottom of the cage. Urine output was determined hourly for a period of four hours. Urine osmolality was measured using a micro-osmometer. Urinary electrolytes $\left(\mathrm{Na}^{+}\right.$and $\left.\mathrm{K}^{+}\right)$were determined by flame photometry.

Experiment 2 - Screening for diuretic activity of high and low molecular mass fractions

Forty rats were randomly divided into 4 groups. Rats in the 4 groups were treated as follows.

Group 1-Distilled water

Group 2 - Low molecular mass fraction

Group 3 - High molecular mass fraction

Group 4-Frusemide

These animals were subjected to the same experimental procedure as described under Experiment 1.

Experiment 3-Screening for the effect of long term administration of $A$. lanata on renal structure and function of rats

Eighteen male rats were randomly assigned to six groups (sample size was limited to 3 rats in each group due to limited availability of resources). The animals in each group were fed with the different solutions as given in Experiment 1. All treatments were given doses of $18 \mathrm{ml} / \mathrm{kg}$ of rat, which was comparable to that given to humans on the basis of relative weights (11). All treatments were given once daily orally for 30 days by a metal oro-gastric tube (12). 


\section{Effect on renal function}

On the $30^{\text {th }}$ day of the experiment, test animals were kept separately in metabolic cages and urine was collected for 24 hours. On the $31^{\text {st }}$ day before the dissection, blood was drawn from the tail vein. Blood was centrifuged and serum was separated. Serum and urine samples were used to determine the creatinine clearance of each rat. Creatinine levels in serum and urine were determined spectrophoto-metrically using a creatinine reagent kit (Cat. no. CR 510, RANDOX Laboratories Ltd. UK). Creatinine clearance was calculated to study the effect of long term administration of $A$. lanata on the renal function of rats.

\section{Effect on renal structure}

On the $31^{\text {st }}$ day of the experiment animals were anaesthetized by ether inhalation. Then animals were dissected through a mid ventral laparotomy and their kidneys, bladder and ureters were harvested and fixed separately in Duboseq Brazil Solution (DBS). These specimens were processed, embedded in wax and $5 \mu \mathrm{m}$ sections were cut. These thin sections of harvested organs were stained with haematoxylin and eosin. The stained sections were examined light microscopically for histological changes.

\section{Results}

\section{Diuretic activity of crude plant extract}

The hourly mean total urine output, urine osmolality and electrolyte excretion during the 4 hours of experimental time period are summarized in Tables 1 and 2. It is evident that there is an increase in the urine output in the groups of rats fed with aqueous plant extracts compared to those in the negative control group (water). When compared with the negative controls fed only water, in groups of rats fed with $100 \mathrm{~g} / 200 \mathrm{ml}$ of dried and fresh plant extracts, a significant increase in the mean total urine output was evident after the $3^{\text {rd }}$ hour. In the frusemide treated rats, a significantly increased urine output was evident at the end of the $2^{\text {nd }}$ and $3^{\text {rd }}$ hours.

Animals treated with plant extracts and frusemide showed higher urinary osmolality compared to the negative control group during each hour. In the $1^{\text {st }}$ hour and $3^{\text {rd }}$ hour, rats fed with $100 \mathrm{~g} / 200 \mathrm{ml}$ of both fresh and dried plant extracts showed a significant increase in urine osmolality. The highest urine osmolality was observed in the $4^{\text {th }}$ hour in all groups except the rats in the group fed with AL50DR. However, it was not statistically significant.

$\mathrm{Na}^{+}$excretion was significantly high only in animals treated with frusemide. In the $4^{\text {th }}$ hour AL50FR and AL100FR showed slight increase in $\mathrm{Na}^{+}$excretion but that was not significant. There was a significant increase in $\mathrm{K}^{+}$excretion compared to the negative control during $1^{\text {st }}$ hour following different treatments. Also there was a significant increase in excretion of $\mathrm{K}^{+}$during the $3^{\text {rd }}$ hour in rats who were given AL100FR, AL50DR and AL100DR solutions.

\section{Diuretic activity of high and low molecular mass fractions}

The hourly mean total urine output, urine osmolality and electrolyte excretion during the 4 hours of experimental time period are summarized in Tables 3 and 4 . Rats fed with low molecular mass fraction had significant increase in urine output after $2^{\text {nd }}$, $3^{\text {rd }}$ and $4^{\text {th }}$ hours, whereas rats fed with high molecular mass fraction had a significant increase in urine output only after $2^{\text {nd }}$ and $3^{\text {rd }}$ hours compared to the rats in the negative control group. Urine osmolality was also significantly high in the group of rats fed with low molecular mass fraction. Significantly increased electrolyte excretion was also observed in the group of rats fed with the low molecular mass fraction. 


\section{Effect of long term administration of} A. lanata on renal structure and function

Mean creatinine clearance and the light microscopic appearance of the specimens following long term administration of different treatments are shown in Table 5. Following long term administration of the different treatments there was no significant difference in serum creatinine clearance, compared to values in the negative control group.

When histological sections of the specimens (kidneys, ureters and bladder) of rats treated with A. lanata extracts were compared with the specimens of the control groups, there was no remarkable difference.

Table 1. Mean total urine output (UOP) after each hour and urine osmolality (Uos) in rats after feeding of crude aqueous plant extracts of $A$. lanata

\begin{tabular}{|c|c|c|c|c|c|c|}
\hline \multirow[t]{2}{*}{ Treatment } & \multirow{2}{*}{\multicolumn{2}{|c|}{$\begin{array}{c}\text { No. of } \\
\text { animals }\end{array}$}} & \multicolumn{4}{|c|}{$\mathrm{UOP}(\mathrm{ml} / \mathrm{rat})$ and Uos (mOsm $/ \mathrm{kg})$} \\
\hline & & & $1 \mathrm{~h}$ & $2 \mathrm{~h}$ & $3 \mathrm{~h}$ & $4 \mathrm{~h}$ \\
\hline \multirow[t]{2}{*}{ Water } & $6^{a}$ & UOP & $1.72 \pm 0.25$ & $2.45 \pm 0.27$ & $2.45 \pm 0.27$ & $2.84 \pm 0.26$ \\
\hline & $6^{b}$ & Uos & $70.2 \pm 5.49$ & $172 \pm 22.7$ & $272.3 \pm 22.5$ & $465 \pm 13$ \\
\hline \multirow[t]{2}{*}{ AL50FR } & $6^{a}$ & UOP & $1.85 \pm 0.43$ & $2.74 \pm 0.20$ & $3.37 \pm 0.2$ & $0.03 \pm 0.41$ \\
\hline & $6^{b}$ & Uos & $113.2 \pm 13.3^{*}$ & $234 \pm 8.84$ & $435 \pm 12$ & $760 \pm 8.0$ \\
\hline \multirow[t]{2}{*}{ AL100FR } & $6^{a}$ & UOP & $2.12 \pm 0.37$ & $2.52 \pm 0.31$ & $3.83 \pm 0.44^{*}$ & $3.83 \pm 0.44$ \\
\hline & $6^{b}$ & Uos & $143.3 \pm 12.3^{*}$ & $397 \pm 13$ & $625 \pm 70.6^{*}$ & 1096 \\
\hline \multirow[t]{2}{*}{ AL50DR } & $6^{b}$ & Uos & $2.20 \pm 0.49$ & $2.98 \pm 0.31$ & $3.37 \pm 0.19$ & $3.37 \pm 0.18$ \\
\hline & $6^{b}$ & Uos & $82.6 \pm 1.69$ & $310.3 \pm 95$ & $478 \pm 32.2^{*}$ & $\bullet$ \\
\hline \multirow[t]{2}{*}{ AL100DR } & $6^{b}$ & Uos & $2.02 \pm 0.46$ & $3.28 \pm 0.78$ & $3.95 \pm 0.87^{*}$ & $4.90 \pm 0.56$ \\
\hline & $6^{b}$ & Uos & $176.2 \pm 22.0^{*}$ & $371.3 \pm 23.1$ & $852.2 \pm 169^{*}$ & $853.3 \pm 15.4$ \\
\hline \multirow[t]{2}{*}{ Frusemide } & $6^{a}$ & UOP & $2.48 \pm 0.24$ & $4.90 \pm 0.41^{*}$ & $6.03 \pm 0.66^{*}$ & $6.76 \pm 0.86$ \\
\hline & $6^{b}$ & Uos & $161.7 \pm 29.1^{*}$ & $259.2 \pm 21.1^{*}$ & $344.4 \pm 12$ & $532 \pm 62.4$ \\
\hline
\end{tabular}

1. * Significantly different from the negative control (water) - p<0.05, Mann-Whitney U test.

2. AL50FR $-50 \mathrm{~g} / 200 \mathrm{ml}$ of fresh A. lanata crude extract AL100FR - $100 \mathrm{~g} / 200 \mathrm{ml}$ of fresh $A$. lanata crude extract AL50DR $-50 \mathrm{~g} / 200 \mathrm{ml}$ of dried A. lanata crude extract AL100DR $-100 \mathrm{~g} / 200 \mathrm{ml}$ of dried A. lanata crude extract

3. - Rats of this group did not pass urine at all.

4. a The urine output of some rats was negligible at times and some did not pass urine at all in which case the urine output of such rats was considered as zero.

5. ${ }^{b}$ Initially number of rats in each group was $\operatorname{six}(n=6)$. The number of samples considered in the analysis of urine osmolality due to the reason mentioned above was

Water $-1 h(n=6), 2 h(n=4), 3 h(n=4), 4 h(n=2)$

AL50FR - 1h ( $n=5), 2 h(n=4), 3 h(n=2), 4 h(n=2)$

AL100FR - 1h $(n=4), 2 h(n=2), 3 h(n=3), 4 h(n=1)$

AL50DR - $1 h(n=5), 2 h(n=4), 3 h(n=4)$

AL100DR - $1 h(n=5), 2 h(n=3), 3 h(n=4), 4 h(n=3)$

Frusemide $-1 h(n=6), 2 h(n=6), 3 h(n=5), 4 h(n=4)$ 
Table 2. Urinary electrolyte excretion $\left(\mathrm{Na}^{+}\right.$and $\left.\mathrm{K}^{+}\right)$in rats after feeding of crude aqueous plant extracts of $A$. lanata

\begin{tabular}{|c|c|c|c|c|c|c|}
\hline \multirow{2}{*}{ Treatment } & \multirow{2}{*}{\multicolumn{2}{|c|}{$\begin{array}{c}\text { No. of } \\
\text { animals }\end{array}$}} & \multicolumn{4}{|c|}{$\mathrm{Na}^{+}$and $\mathrm{K}^{+}(\mathrm{mmol} / \mathrm{l})$} \\
\hline & & & $1 \mathrm{~h}$ & $2 \mathrm{~h}$ & $3 \mathrm{~h}$ & $4 \mathrm{~h}$ \\
\hline \multirow[t]{2}{*}{ Water } & $6^{a}$ & $\mathrm{Na}^{+}$ & $6.3 \pm 2.6$ & $13 \pm 8.4$ & $23.7 \pm 12.7$ & $3.7 \pm 3.8$ \\
\hline & & $\mathrm{K}^{+}$ & $7.82 \pm 1.0$ & $26.2 \pm 2.7$ & $34 \pm 2.8$ & $55.8 \pm 2.2$ \\
\hline \multirow[t]{2}{*}{ AL50FR } & $6^{a}$ & $\mathrm{Na}^{+}$ & $10.6 \pm 2.2$ & $16.8 \pm 5.9$ & $38.5 \pm 0.5$ & $69.5 \pm 5.5$ \\
\hline & & $\mathrm{K}^{+}$ & $16.2 \pm 2.8^{*}$ & $45.3 \pm 1.4$ & $82 \pm 2.0$ & $139.5 \pm 19$ \\
\hline \multirow[t]{2}{*}{ AL100FR } & $6^{a}$ & $\mathrm{Na}^{+}$ & $14 \pm 3.7$ & $19 \pm 4$ & $25 \pm 4.9$ & 67 \\
\hline & & $\mathrm{K}^{+}$ & $25.6 \pm 5.6^{*}$ & $27.1 \pm 15.4$ & $119.8 \pm 13^{*}$ & 194 \\
\hline \multirow[t]{2}{*}{ AL50DR } & $6^{a}$ & $\mathrm{Na}^{+}$ & $3.6 \pm 0.50$ & $6 \pm 1.5$ & $16 \pm 2.4$ & - \\
\hline & & $\mathrm{K}^{+}$ & $23.3 \pm 0.95^{*}$ & $122.8 \pm 27$ & $111.3 \pm 0.3^{*}$ & - \\
\hline \multirow[t]{2}{*}{ AL100DR } & $6^{\mathrm{a}}$ & $\mathrm{Na}^{+}$ & $7.8 \pm 3.0$ & $6.3 \pm 3.4$ & $16.8 \pm 8$ & $14.7 \pm 5.4$ \\
\hline & & $\mathrm{K}^{+}$ & $47.2 \pm 9.2^{*}$ & $131.3 \pm 12.9$ & $192.3 \pm 1.7^{*}$ & $173 \pm 21$ \\
\hline \multirow[t]{2}{*}{ Frusemide } & $6^{a}$ & $\mathrm{Na}^{+}$ & $40.5 \pm 13^{*}$ & $67.7 \pm 9.6^{*}$ & $111.7 \pm 12^{*}$ & $03 \pm 8.5^{*}$ \\
\hline & & $\mathrm{K}^{+}$ & $17 \pm 0.9^{*}$ & $33.8 \pm 4.3$ & $39.9 \pm 4.9$ & $81.9 \pm 29$ \\
\hline
\end{tabular}

1. * Significantly different from the negative control (water) - $p<0.05$, Mann-Whitney U test.

2 - Rats of this group did not pass urine at all.

3. " Initially number of rats in each group was $\operatorname{six}(n=6)$. The urine output of some rats was negligible at times and some did not pass urine at all in which case the urine output of such rats was considered as zero. These samples were not considered in the analysis.

Table 3. Mean total urine output (UOP) after each hour and urine osmolality (Uos) in rats after feeding of low and high molecular mass fractions of $A$. lanata

\begin{tabular}{|c|c|c|c|c|c|c|}
\hline \multirow{2}{*}{ Treatment } & \multirow{2}{*}{\multicolumn{2}{|c|}{$\begin{array}{c}\text { No. of } \\
\text { animals }\end{array}$}} & \multicolumn{4}{|c|}{$\mathrm{UOP}(\mathrm{ml} / \mathrm{rat})$ and $\mathrm{Uos}(\mathrm{mOsm} / \mathrm{kg})$} \\
\hline & & & $1 \mathrm{~h}$ & $2 \mathrm{~h}$ & $3 \mathrm{~h}$ & $4 \mathrm{~h}$ \\
\hline Water & & & $\begin{array}{r}1.67 \pm 0.3 \\
92 \pm 10.7\end{array}$ & & $\begin{array}{r}2.91 \pm 0.20 \\
351.2 \pm 113\end{array}$ & \\
\hline $\begin{array}{l}\text { Low mol. } \\
\text { mass fraction }\end{array}$ & $\begin{array}{l}10^{\mathrm{a}} \\
10^{\mathrm{b}}\end{array}$ & & $\begin{aligned} 2.46 & \pm 0.58 \\
209.3 & \pm 26^{*}\end{aligned}$ & $\begin{array}{r}4.14 \pm 0.38^{*} \\
447.9 \pm 53^{*}\end{array}$ & $\begin{array}{l}4.78 \pm 0.34^{*} \\
749 \pm 47\end{array}$ & $\begin{array}{r}5.38 \pm 0.35^{*} \\
899.8 \pm 41.1^{*}\end{array}$ \\
\hline $\begin{array}{l}\text { High mol. } \\
\text { mass fraction }\end{array}$ & $\begin{array}{l}10^{\mathrm{a}} \\
10^{\mathrm{b}}\end{array}$ & $\begin{array}{l}\text { UOP } \\
\text { Uos }\end{array}$ & $\begin{array}{r}2.25 \pm 0.32 \\
106 \pm 6.3\end{array}$ & $\begin{aligned} 3.38 & \pm 0.26^{*} \\
188.6 & \pm 22.6\end{aligned}$ & $\begin{aligned} 4.05 & \pm 0.34^{*} \\
497.5 & \pm 106\end{aligned}$ & $\begin{aligned} 4.19 & \pm 0.38 \\
631.3 & \pm 40.4\end{aligned}$ \\
\hline Frusemide & $\begin{array}{l}10^{\mathrm{a}} \\
10^{\mathrm{b}}\end{array}$ & $\begin{array}{l}\text { UOP } \\
\text { Uos }\end{array}$ & $\begin{array}{r}1.73 \pm 0.34 \\
141.2 \pm 4.03^{*}\end{array}$ & $\begin{aligned} 3.94 & \pm 0.27^{*} \\
238.4 & \pm 16\end{aligned}$ & $\begin{aligned} 5.05 & \pm 0.48^{*} \\
352.8 & \pm 25\end{aligned}$ & $\begin{array}{l}6.04 \pm 0.38^{*} \\
58.5 \pm 172\end{array}$ \\
\hline
\end{tabular}

1. * Significantly different from the negative control (water) $-p<0.05$, Mann-Whitney $U$ test.

2. "The urine output of some rats was negligible at times and some rats sometimes did not pass urine at all in which case the urine output of such rats was considered as zero.

3. ' Initially number of rats in each group was ten $(n=10)$. The number of samples considered in the analysis of urine osmolality due to the reason mentioned above was

Water $-1 h(n=8), 2 h(n=6), 3 h(n=4), 4 h(n=3)$

Low molecular mass fraction $-1 h(n=8), 2 h(n=7), 3 h(n=2), 4 h(n=5)$

High molecular mass fraction $-1 h(n=9), 2 h(n=7), 3 h(n=6), 4 h(n=2)$

Frusemide $-1 h(n=8), 2 h(n=8), 3 h(n=6), 4 h(n=6)$ 
Table 4. Urinary electrolyte excretion $\left(\mathrm{Na}^{+}\right.$and $\left.\mathrm{K}^{+}\right)$in rats after feeding of low and high molecular mass fractions of $A$. lanata

\begin{tabular}{|c|c|c|c|c|c|c|}
\hline Treatment & No. of & & & $\mathrm{Na}^{+}$and $\mathrm{K}$ & $+(\mathrm{mmol} / \mathrm{l})$ & \\
\hline & animals & & $1 \mathrm{~h}$ & $2 \mathrm{~h}$ & $3 \mathrm{~h}$ & $4 \mathrm{~h}$ \\
\hline Water & $10^{a}$ & $\mathrm{Na}^{+}$ & $3.6 \pm 0.98$ & $5.5 \pm 0.96$ & $27 \pm 9.3$ & $28 \pm 7.7$ \\
\hline & & $\mathrm{K}^{+}$ & $9.02 \pm 1.0$ & $26.2 \pm 5.8$ & $37.6 \pm 3.0$ & $6.2 \pm 22.5$ \\
\hline Low mol. & 10 & $\mathrm{Na}^{+}$ & $37.3 \pm 3.7^{*}$ & $52.3 \pm 10.3^{*}$ & $44.5 \pm 4.5$ & $43.2 \pm 6.6$ \\
\hline mass fraction & & $\mathrm{K}^{+}$ & $42.6 \pm 2.58^{*}$ & $112.9 \pm 17.9^{*}$ & $147.5 \pm 2.5^{*}$ & $238.5 \pm 19.7^{*}$ \\
\hline High mol. & $10^{a}$ & $\mathrm{Na}^{+}$ & $7.44 \pm 1.6$ & $18.9 \pm 5.24$ & $40.4 \pm 9.5$ & $64 \pm 24$ \\
\hline mass fraction & & $\mathrm{K}^{+}$ & $8.62 \pm 0.95$ & $19.8 \pm 3.4$ & $62.3 \pm 9.2$ & $66.7 \pm 1.4$ \\
\hline Frusemide & $10^{a}$ & $\mathrm{Na}^{+}$ & $31.8 \pm 10.5^{*}$ & $60.3 \pm 10^{*}$ & $116.3 \pm 9.6^{*}$ & $113.8 \pm 6.5^{*}$ \\
\hline & & $\mathrm{K}^{+}$ & $14.7 \pm 1.4^{*}$ & $24.4 \pm 4.1$ & $40.3 \pm 3.5$ & $90.9 \pm 19.2$ \\
\hline
\end{tabular}

1. * Significantly different from the negative control (water) - $p<0.05$, Mann-Whitney U test.

2. "Initially number of rats in each group was ten $(n=10)$. The urine output of some rats was negligible at times and some did not pass urine at all in which case the urine output of such rats was considered as zero. These samples were not considered in the analysis.

Table 5. Mean creatinine clearance and effects on renal structure of rats following long term administration of crude aqueous plant extracts of $A$. lanata

Solution Creatinine Clearance $(\mathrm{ml} / \mathrm{min})$

Effects on renal structure (Light microscopic appearance)

\begin{tabular}{ll}
\hline Water & $0.425 \pm 0.096$
\end{tabular}
AL50FR
$0.363 \pm 0.111$
AL100FR
$0.412 \pm 0.017$

$\begin{array}{ll}\text { AL50DR }^{\mathrm{a}} & 0.414 \pm 0.191\end{array}$

$\begin{array}{ll}\text { AL100DR } & 0.140 \pm 0.042\end{array}$

Kidneys, bladder and ureters were normal in appearance

Kidneys, bladder and ureters were normal in appearance

Bladder and ureters did not show any abnormality. Kidneys showed focally congested glomeruli

Bladder and ureters did not show any abnormality. Kidneys showed focally congested glomeruli Bladder and ureters did not show any abnormality. Kidneys showed focally congested glomeruli $\begin{array}{ll}\text { Frusemide } & 0.424 \pm 0.070\end{array}$ Kidneys, bladder and ureters were normal in appearance

1. AL50FR $-50 \mathrm{~g} / 200 \mathrm{ml}$ of fresh A. lanata crude extract AL100FR $-100 \mathrm{~g} / 200 \mathrm{ml}$ of fresh $A$. lanata crude extract AL50DR $-50 \mathrm{~g} / 200 \mathrm{ml}$ of dried A. lanata crude extract AL100DR $-100 \mathrm{~g} / 200 \mathrm{ml}$ of dried A. lanata crude extract 2. " One animal died on the $16^{\text {th }}$ day of the experiment. 


\section{Discussion}

Results of this study show that crude aqueous plant extract of $A$. lanata has a diuretic effect on rats when given orally. Our results are comparable with the findings of Prasad et al., (8). Also our results show that the treatment with crude aqueous plant extract has a rapid onset of action and this effect remains for about three hours.

When the diuretic effect was studied further, using high and low molecular mass fractions of $A$. lanata, it shows that low molecular mass fraction is more effective as a diuretic substance compared to the high molecular mass fraction. This difference may be due to the presence of more ingredients responsible for the diuretic effect of $A$. lanata in the low molecular mass fraction.

The precise mechanism of the diuretic effect of the plant extract is not clear. However, the diuretic effect is not similar to the effect produced by frusemide. It may be similar to the effect produced by thiazides as the plant extract too has more effect on $\mathrm{K}^{+}$excretion than $\mathrm{Na}^{+}$excretion.

Further, the results of this preliminary investigation indicate that administration of A. lanata for one month has no toxic effect in the urinary tract of rats.

\section{Conclusion}

This study demonstrates that $A$. lanata plant extract has a diuretic effect. When low and high molecular mass fractions were used, it is evident that low molecular mass fraction has more diuretic activity compared to the high molecular mass fraction. Also administration of $A$. lanata for a period of one month has no significant toxic effects in the urinary tract of rats.

\section{Acknowledgements}

We would like to thank $\mathrm{Mr} \mathrm{H}$ Weerawarna of National Hospital of Colombo, Sri Lanka for helping us in the determination of urinary electrolytes, Mr Muditha Kularatne, Department of Pathology, Faculty of Medicine, Colombo for processing of specimens for histological studies and $\mathrm{Mr} \mathrm{K}$ Perera and Mr K Gamage of Animal House, Faculty of Medicine, Colombo for their assistance.

\section{References}

1. Jayaweera D.M.A. Medicinal plants (Indigenous and Exotic) used in Ceylon, Part 1, The National Science Council of Sri Lanka 1981; 40-41.

2. Kokwaro J.O. Medicinal plants of East Africa. East African Literature Bureau, Kenya; 1976.

3. Rahman A., Said H.M., Ahmad V.U. (Eds). Pakistan Encyclopaedia Planta Medica, Volume 1, Hamdard Foundation Press, Hamdard Centre, Karachi-18, Pakistan 1986; 214.

4. Chandra S., Sastry M.S. Chemical constituents of Aerva lanata. Fitoterapia 1990; 61: 188.

5. Jayasinha P., Warnasuriya D., Dissanayaka H. Medicinal and Aromatic Plant Series, No.7, Information Services Centre, Industrial Technology Institute, Sri Lanka; 1999: 1-7.

6. Udupihille M., Jiffry M.T.M. Diuretic effect of Aerva lanata with water, normal saline and coriander as controls. Indian Journal of Physiology and Pharmacology 1986; 30: 91-97. 
7. Goonaratna Colvin., Thabrew Ira., Wijewardana Kumudu. Does Aerva lanata have diuretic properties? Indian Journal of Physiology and Pharmacology 1993; 37: 135-137.

8. Prasad K.V.S.R.G., Sankarasubramanian S., Guruswami M. N. Pharmacological studies on the roots of Aerva lanata. Arogya Journal of Health Science 1986; 12: 6-13.

9. Ediriweera E.R.H.S.S., Ratnasooriya W.D. Antidiuretic effect of Scoparia dulcis in rats. Journal of Tropical Medicinal Plants 2002; 3: 55-58.

10. Sripanidkulchai Bungorn., Wongpanch
Varima, Laupattarakasem Pisamai, Suwansaksri Jamsai, Jirakulsomchok Dusit. Diuretic effects of selected Thai indigenous medicinal plants in rats. Journal of Ethnopharmacology 2001; 75 : 185-190.

11. Paget G.E., Barnes J.M. Toxicity tests. In: Evaluation of drug activities. Pharmacometrics. Eds: Laurence D.R., Bacharach A.L. 1964; Vol. (1) Chapter (6). London Academic Press. p135.

12. General guidelines for methodologies on research and evaluation of traditional medicine. World Health Organization, Geneva, 2000: 27-31. 